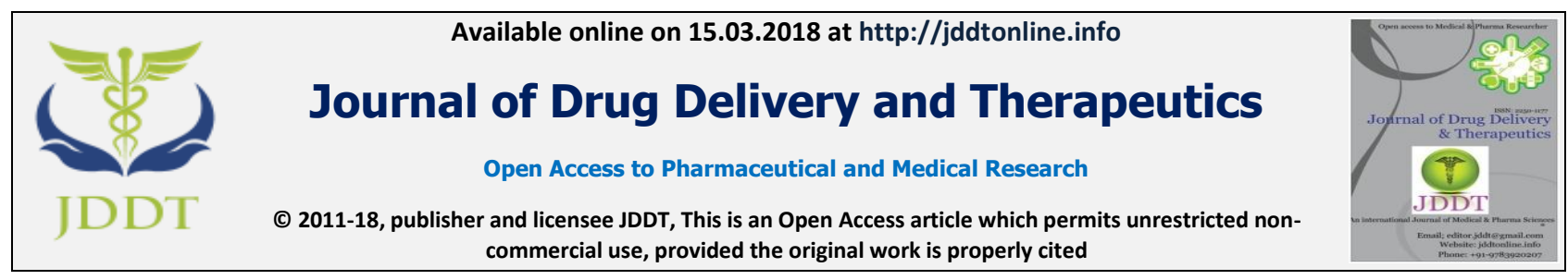

Open $\odot$ Access

Research Article

\title{
ISOLATION AND CHARACTERIZATION OF CHEMICAL COMPOUNDS FROM FRUIT PULP OF CASSIA FISTULA AND THEIR ANTIMICROBIAL ACTIVITY
}

\author{
Deepa Hada* and Kanika Sharma \\ Department of Botany, Mohanlal Sukhadia University, Udaipur-313001 (Rajasthan), India
}

\begin{abstract}
In the present study effect of chloroform fraction of Cassia fistula fruit pulp on cyto-morphological parameters like mycelium width and conidial size of Alternaria solani has been studied. Column chromatography of chloroform extract and TLC fingerprinting of column fractions were also done. Column fractions were screened for antifungal activity and fraction showing best activity was further subjected to GC MS analysis for the purification and identification of the structure of active compound. Result suggested that mycelium width of Alternaria solani increased up to $77.89 \%$ and conidia size of the was reduced up to $97.61 \%$ at $1.25 \mathrm{mg} / \mathrm{ml}(\mathrm{Sub}$ MIC) concentration of the chloroform extract. Eight fractions obtained from column chromatography and fraction no. 2 (FPF-2) showed maximum inhibition i.e. 98.25\% against Alternaria solani. Rf values of TLC bands of column fractions were found between the range from 0.60 to $0.97 \mathrm{~cm}$. GC-MS analysis reveals the presence of butanoic acid, 2-methyl-, Penthiophane (2H-Thiopyran, tetrahydro) and Isopropyl acetate (Acetic acid, 1-methyl ethyl ester). These three compounds are responsible for the antimicrobial activity of Cassia fistula fruit pulp.
\end{abstract}

Keywords: Column chromatography, cytomorphology, Gas chromatography/mass, spectrometry Alternari solania, Cassia fistula

Article Info: Received 09 Jan, 2018; Review Completed 13 Feb, 2018; Accepted 13 Feb, 2018; Available online 15 March, 2018

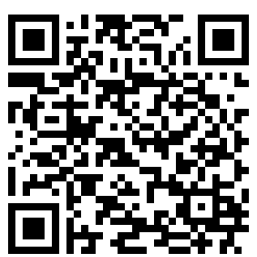

\section{Cite this article as:}

Hada D, Sharma K, Isolation and characterization of chemical compounds from fruit pulp of Cassia fistula and their antimicrobial activity, Journal of Drug Delivery and Therapeutics. 2018; 8(2):15-20

DOI: http://dx.doi.org/10.22270/jddt.v8i2.1664

*Address for Correspondence

Deepa Hada, Department of Botany, Mohanlal Sukhadia University, Udaipur-313001 (Rajasthan), India

\section{INTRODUCTION}

Recent trends favour the use of alternative substances derived from natural plant extracts to control pests. The use of natural products for the control of fungal diseases in plants is considered as an interesting alternative to synthetic fungicides due to their less negative impacts on the environment. These natural products or plant extracts can be exploited either as leads for chemical synthesis of new agrochemicals, or as commercial products in their own right, or as a source of inspiration to biochemists for the development of new bioassays capable of detecting other, structurally simpler, compounds with the same mode of action' (Lange et al., 1993).

Plants have endless ability to synthesize various secondary metabolites which acts as main agents for plant defence mechanisms against microorganisms. These secondary metabolites are antimicrobial in nature and the use of various plant extracts for growth inhibition of plant pathogenic fungi. The biological and molecular action of plants secondary metabolites induces various morphological and cytological changes in the microorganisms including fungi and bacteria ${ }^{2}$ (Wilson et al., 1997).

All morphological/cytomorphological alterations may be related to the effect of secondary metabolites on enzymatic reactions/specific enzymes regulating cell wall synthesis, changing/disturbing membrane permeability, thickening of cell wall by binding to the receptors as well as disruption of cell membrane ${ }^{3}$ (Polya 2003). 
Cassia fistula (Linn.) belongs to family Fabaceae and Sub-family Caesalpinioideae. It is a very common plant known for its medicinal properties and is semi-wild in nature. It is distributed in various regions including Asia, South Africa, China, West Indies and Brazil. It is commonly known as Amaltas and in English it is popularly called "Indian Laburnum" and has been extensively used in Ayurvedic system of medicine for various ailments. It is widely used in traditional medicinal system of India. The plant parts are used in folk remedies for tumors of the abdomen, glands, liver, stomach, throat cancer carcinomata and impostumes of the uterus. Root is useful in fever, heart diseases, retained excretions and biliousness ${ }^{4}$ (Nadkarni, 2009).

Alternaria solani is the causal agent of early blight and important foliar pathogen of potato worldwide. It belongs to large long beaked and noncatenated spores group of the genus Alternaria ${ }^{5}$ (Simmons, 2000). It shows dark black to brown circular colony morphology on Potato dextrose agar (PDA) media. The mycelium consisted of septate, branched, light brown hyphae which turned darker with age. They reproduces asexually by means of conidia these Spores or conidia are the primary agent for infecting host plants for many plant pathogenic fungi ${ }^{6}$ (Heaney et al., 2000).

Due to the damage caused by plant diseases, continuous research is essential for developing new control methods to increase or even maintain current levels of crop production. Nowadays, the natural products and medicinal plants are a subject of great global interest for the discovery of new antimicrobial agents. One of the main procedures used in search of new biologically active substances is the systematic screening of plant extracts for their antimicrobial activity. This procedure has been a source of useful agents to control the microbial survival $^{7}$ (Tuzun \& Kloepper, 1995).

In the present study effect of different concentrations ranging up to MIC of chloroform fraction of Cassia fistula fruit pulp on cyto-morphological parameters like mycelium width and conidial size of Alternaria solani has been studied. Column fractions of chloroform extract were also screened for antifungal activity and fraction showing best activity was further subjected to GC MS analysis for the purification and identification of structure of active compound.

\section{MATERIALS AND METHODS}

\section{Effect of chloroform extract on morphology of Alternaria solani}

Chloroform extract was prepared by the hot extraction method suggested by Harborne, 1984 ${ }^{8}$. Minimum Inhibitory Concentration (MIC) of this extract was determined by broth dilution method ${ }^{9}$ (Collee et al., 1996). Effect of chloroform extract on various morphological and cytological parameters of Alternaria solani was studied. Test fungus was treated with increasing concentrations of the extract up till MIC. A small fungal biomass consisting of mycelium, and spores were removed from each tube and microscopic examination was done after staining with cotton blue and mounting in lacto-phenol. Changes in mycelium width, conidia size and no. of conidia were also observed with the help of Olympus trinocular research microscope BX- 51 and analyzed by ocular micrometer using microscope. Conidia/ spore counting were done by haemocytometer.

\section{Column chromatography of chloroform extract}

$10 \mathrm{gm}$ of dried and partially purified chloroform extract was dissolved in their mobile phase i.e. $50 \mathrm{ml}$ Chloroform, $50 \mathrm{ml}$ ethyl acetate, $30 \mathrm{ml}$ ethanol and 100 $\mu \mathrm{l}$ acetic acid. Thus prepared solution was subjected to column chromatography. Glass column (Merck: 120-240 $\mathrm{mm}$ ) filled with $650 \mathrm{gm}$ of silica gel was used for column chromatography. Different fractions of extract containing different secondary metabolites were collected according to the color bands developed in column. These fractions were dried in rotary vacuum evaporator under reduced pressure. Dried fractions were screened for their antifungal activity. The fraction showing best antifungal activity was subjected to further purification and characterization for active molecule via gas chromatography and mass spectrometry.

\section{TLC Fingerprinting of column fractions}

TLC fingerprinting of chloroform fraction of fruit pulp performed using precoated silica gel $60 \mathrm{~F}_{254}$ TLC plates (E-Merck) of uniform thickness (20mm x 20mm). A 10 $\mathrm{cm}$ length of TLC plate was cut and marked carefully. $10 \mu \mathrm{l}$ of plant extract was spotted onto the marked plate with the help of a capillary tube or pipette. TLC finger printing was derivatized with anisaldehyde sulphuric acid reagent followed by heating at $100^{\circ} \mathrm{C}$ till coloured bands of various secondary metabolites appeared. The observations were taken before and after derivatization, in visible as well as UV rays. $R_{\mathrm{f}}$ value of the extracted secondary metabolites were calculated as follows:

$$
\mathrm{Rf}=\frac{\text { Distance traveled by substance }}{\text { Distance traveled by solvent }}
$$

\section{Assay of Antifungal Activity of column fractions}

Antifungal activity of various column fractions against Alternaria solani was done by Poison food technique ${ }^{10}$ (Grover and Moore, 1962). $100 \mathrm{mg}$ of extract was dissolved in $10 \mathrm{ml}$ solvent (acetone) to prepare stock solution of $10 \mathrm{mg} / \mathrm{ml}$ concentration. $9 \mathrm{ml}$ of molten PDA medium was poured into test tubes and then autoclaved. The molten sterilized medium along with $1 \mathrm{ml}$ of stock solution was poured into Petri plates. In the control set no extract was used. After the solidification of the media, $6 \mathrm{~mm}$ inoculum disc of 7 days old culture of the fungus was aseptically inoculated upside down in the centre of the petriplate and incubated at $27 \pm 2^{\circ} \mathrm{C}$. Culture control and acetone control were also maintained along with test samples. Antifungal activity was measured as a function of increase in growth of $6 \mathrm{~mm}$ disc of inoculum.

The average diameter of the fungal colonies was measured on the 7 th day of incubation and percentage of mycelial growth inhibition was calculated by the following formula given below.

Percent Mycelial growth inhibition = gc-gt $/ \mathrm{gc} \times 100$ 
Where,

$\mathrm{gc}=$ Growth of mycelial colony after incubation period in control set subtracting the diameter of inoculums disc.

gt $=$ Growth of mycelial colony after incubation period in treatment set subtracting the diameter of inoculum disc.

\section{Identification and Structure Determination by GC- MS (Gas chromatography/mass spectrometry)}

For identification of active antifungal compound from selected fraction, the sample was sent to Sophisticated Instrumentation Centre for Applied Research and Testing (SICART) Anand (Gujarat, India). The GC MS analysis were performed on a GC (Perkin-Elmer) system coupled to Perkin- Elmer Turbo Mass MS. HP1-MS capillary column $(30 \mathrm{~m} \times 0.25 \mu \mathrm{m} \times 0.25 \mu \mathrm{m})$ was used under the following conditions: oven temperature programmed from $70^{\circ} \mathrm{C}$ for $10 \mathrm{~min}$, then gradually increased at $290^{\circ} \mathrm{C}$ at $3 \mathrm{~min}$; injector temperature, $250^{\circ} \mathrm{C}$, carrier gas Helium, flow rate $1 \mathrm{ml} / \mathrm{min}$; the volume of injected sample was $1 \mu \mathrm{l}$; split ratio $1: 60$; ionization energy $70 \mathrm{eV}$ : Run time $40 \mathrm{~min}$. The relative percentage amount of each component was calculated by comparing its average peak area to the total areas. The identification of the separated compounds was achieved through retention indices and mass spectrometry by the comparing mass spectra of the unknown peaks with those stored in the NIST/EPA/NIH Mass Spectral Library 2014.

\section{RESULTS AND OBSERVATIONS}

Effect of chloroform extract on mycelial width and conidia size of Alternaria solani are presented in Figure 1 and 2. A gradual decrease in conidia size, while swelling of hypha was observed due to treatment with extract. Mycelium width of Alternaria solani increased up to $77.89 \%$ at $1.25 \mathrm{mg} / \mathrm{ml}$ concentration of the extract. Conidia size of the Alternaria solani was reduced up to $97.61 \%$ at $1.25 \mathrm{mg} / \mathrm{ml}$ (Sub MIC) concentration of the chloroform extract. The inhibition of conidia and mycelia formation was observed at MIC of the extract i.e. $2.5 \mathrm{mg} / \mathrm{ml}$.

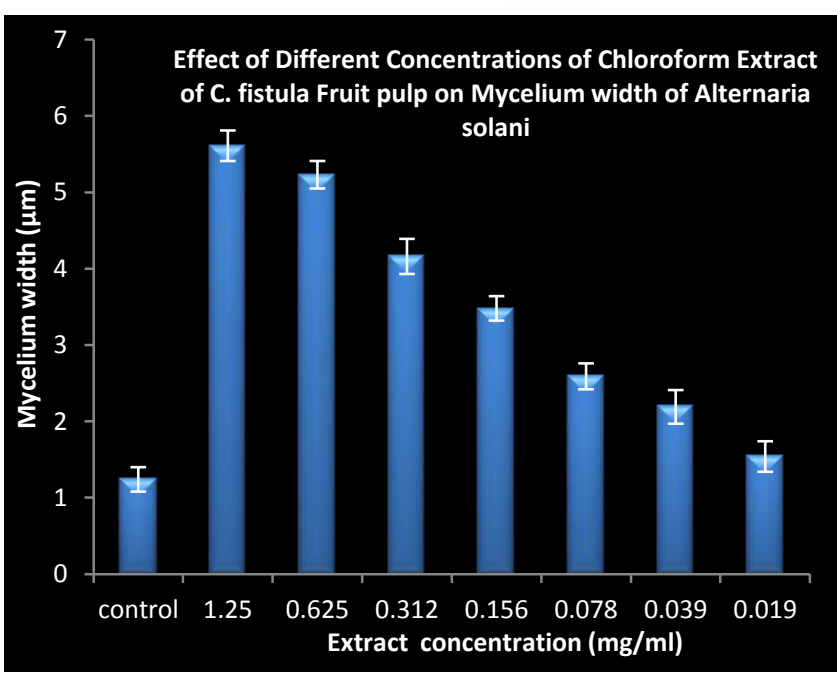

Figure 1: Effect of Different Concentrations of Chloroform Extract of Cassia fistula Fruit pulp on Mycelium width of Alternaria solani
Some abnormalities were also observed in reproductive structures of Alternaria solani after treatment with extracts. At $1.25 \mathrm{mg} / \mathrm{ml}$ concentration of extract dichotomous branching in the conidiophores was observed and conidia were found directly attached to the mycelia.

Eight fractions obtained from column chromatography were subjected to thin layer chromatography. TLC of each fraction showed presence of more than one band. Bands on TLC plates were observed before and after derivatization under UV light at $360 \mathrm{~nm}$ (Figure $3 \mathrm{~A}, \mathrm{~B}$, C). Colour of bands changed after spraying anisaldehyde on the TLC plates.

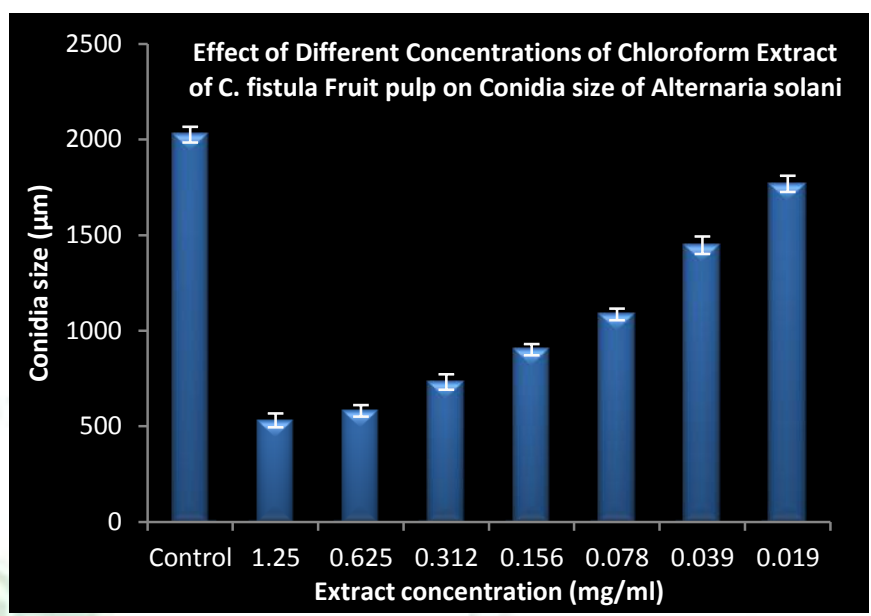

Figure 2: Effect of Different Concentrations of Chloroform Extract of Cassia fistula Fruit pulp on Conidia size of Alternaria solani


Figure 3: Thin Layer Chromatography (TLC) of Various Column Fractions of Chloroform Extract of Cassia fistula Fruit pulp
A: $\quad$ Under visible light
B: $\quad$ Under UV light (Before derivatization)
C: $\quad$ Under UV light (After derivatization) 
At different Rf values, bands of various colours viz. dark yellow, light yellow, light green, dark green, light grey, yellow green, light brown, dark brown, and light pink were observed for TLC developed from column fractions of chloroform fraction of fruit pulp extract. It indicates that this fraction contains a group of compounds. Rf values of TLC bands of column fractions were found between the range from 0.60 to $0.97 \mathrm{~cm}$.

All column fractions showed significant antifungal activity but fraction no. 2 (FPF-2) showed maximum $(98.25 \%)$ inhibition followed by fraction no. $1(86.46 \%)$, fraction no. $4(83.41 \%)$ and fraction no. $5(62.45 \%)$. The percent mycelial growth inhibition observed with fraction no $3,6,7,8$ was $61.14 \%, 59.83 \%, 53.28 \%$ and $47.16 \%$ respectively (Figure 4 ).

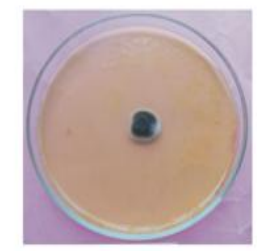

1

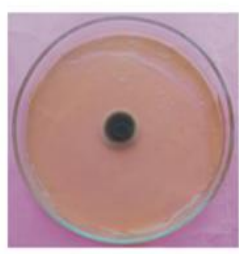

4

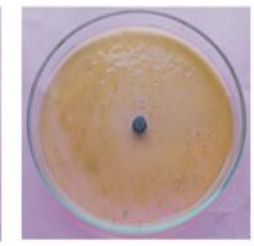

2

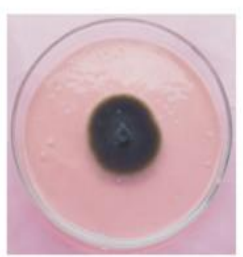

5

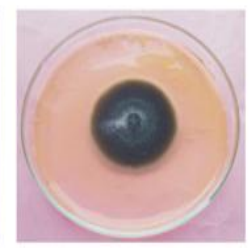

3

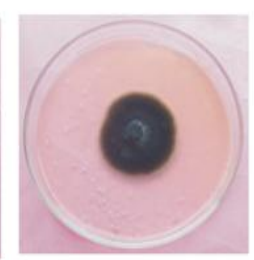

6

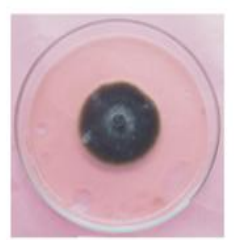

7

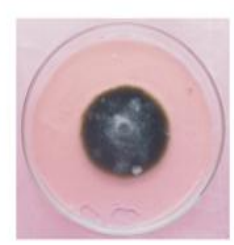

8
Figure 4: Antifungal Activity of Column Fractions (1-8 Numbers) of Chloroform Extract of Cassia fistula Fruit pulp against Alternaria solani

The fraction no. 2 (FPF-2) showed most significant activity against test fungus was subjected to GC MS analysis for the separation and identification of active principle. The chromatogram obtained in GC MS analysis is given in Figure 5. Three compounds identified, the most prevailing compounds were Butanoic acid, 2-methyl- $(90.36 \%)$ at retention time 3.68, Penthiophane (2H-Thiopyran, tetrahydro) $(6.16 \%)$ at retention time 2.80 and Isopropylacetate (Acetic acid, 1-methylethyl ester) $(3.48 \%)$ at retention time 2.04 . The presence of compounds was confirmed after comparing with NIST/EPA/NIH Mass Spectral Library 2014. The mass spectrum of identified compounds is given in Figure 6 to 8 .

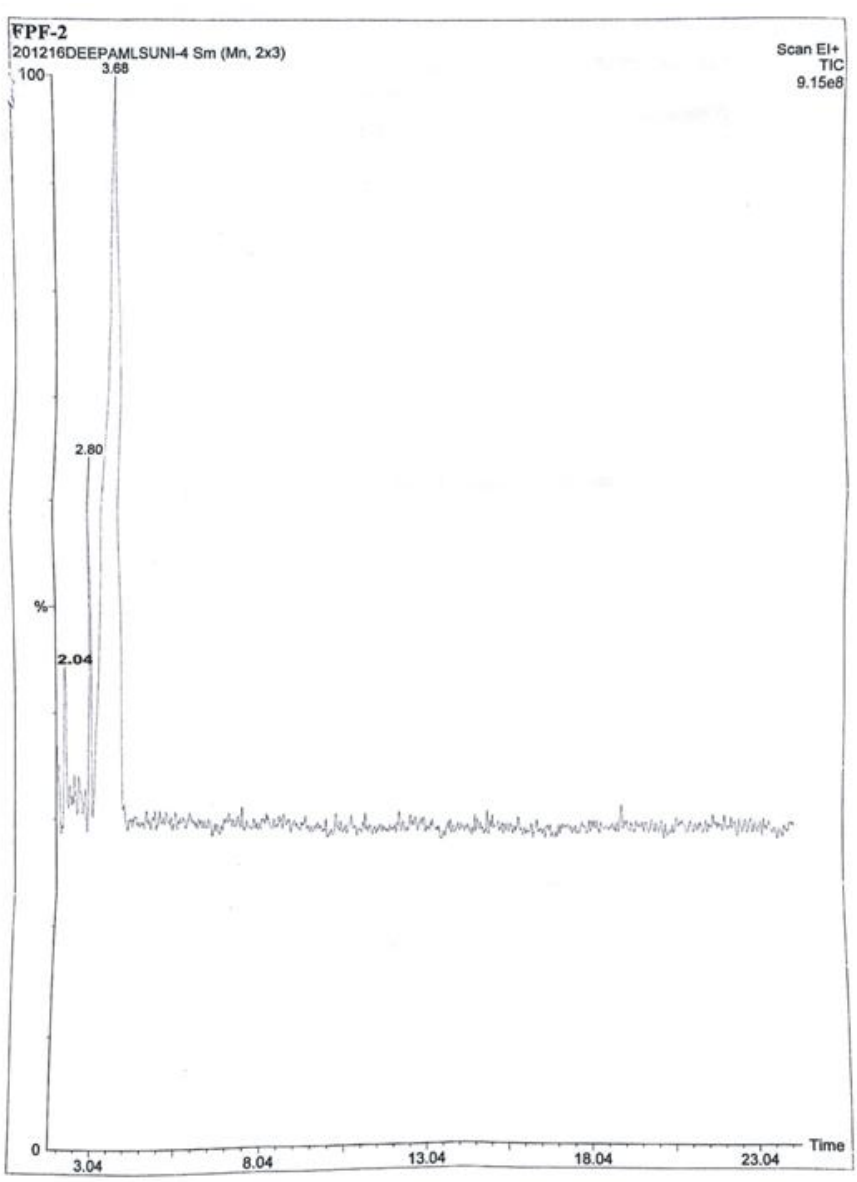

Figure 5: Gas Chromatography- Mass Spectrometry Analysis of Column Fraction no. 2 of Chloroform Extract of Cassia fistula Fruit pulp

Isopropylacetate (Acetic acid, 1-methylethyl ester)

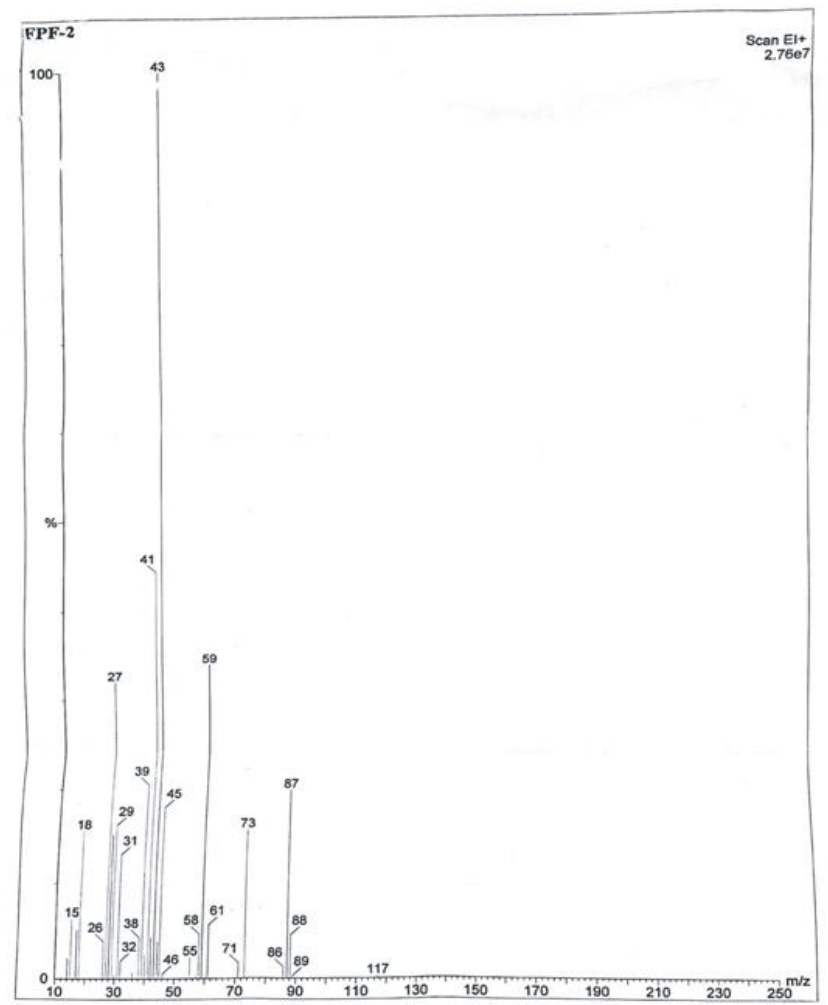

Figure 6: Mass Spectrum of Isopropylacetate (Acetic acid, 1-methylethyl ester) 
Penthiophane (2H-Thiopyran, tetrahydro)

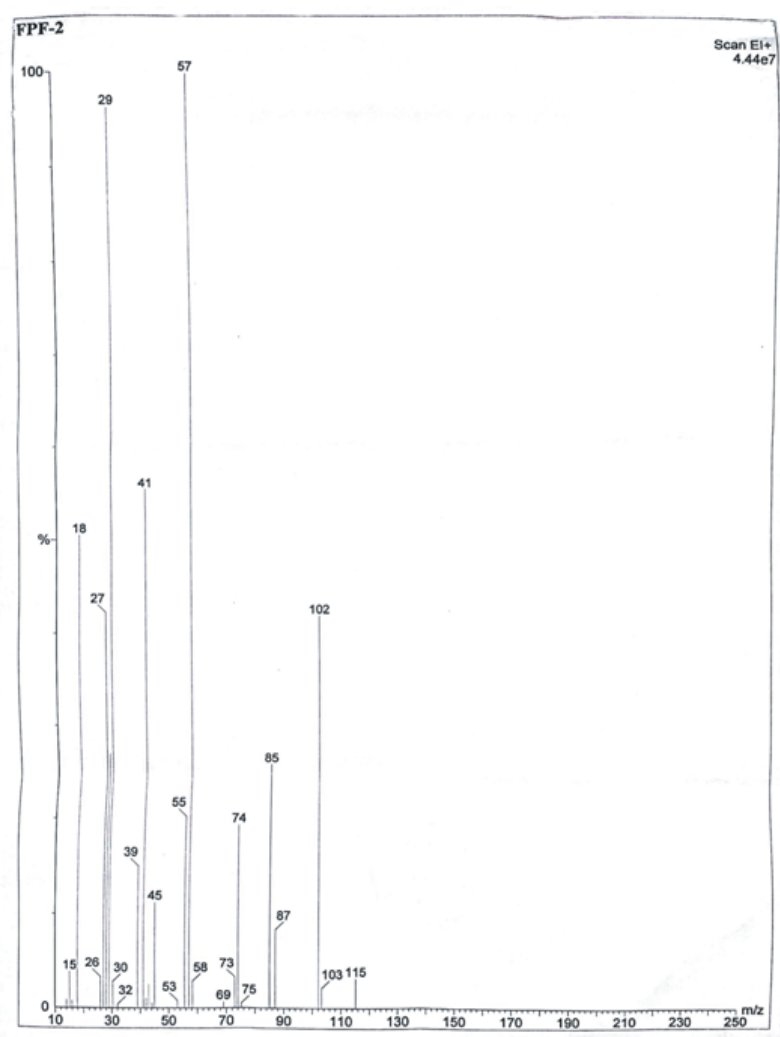

Figure 7: Mass Spectrum of Penthiophane (2HThiopyran, tetrahydro)

Butanoic acid, 2-methyl-

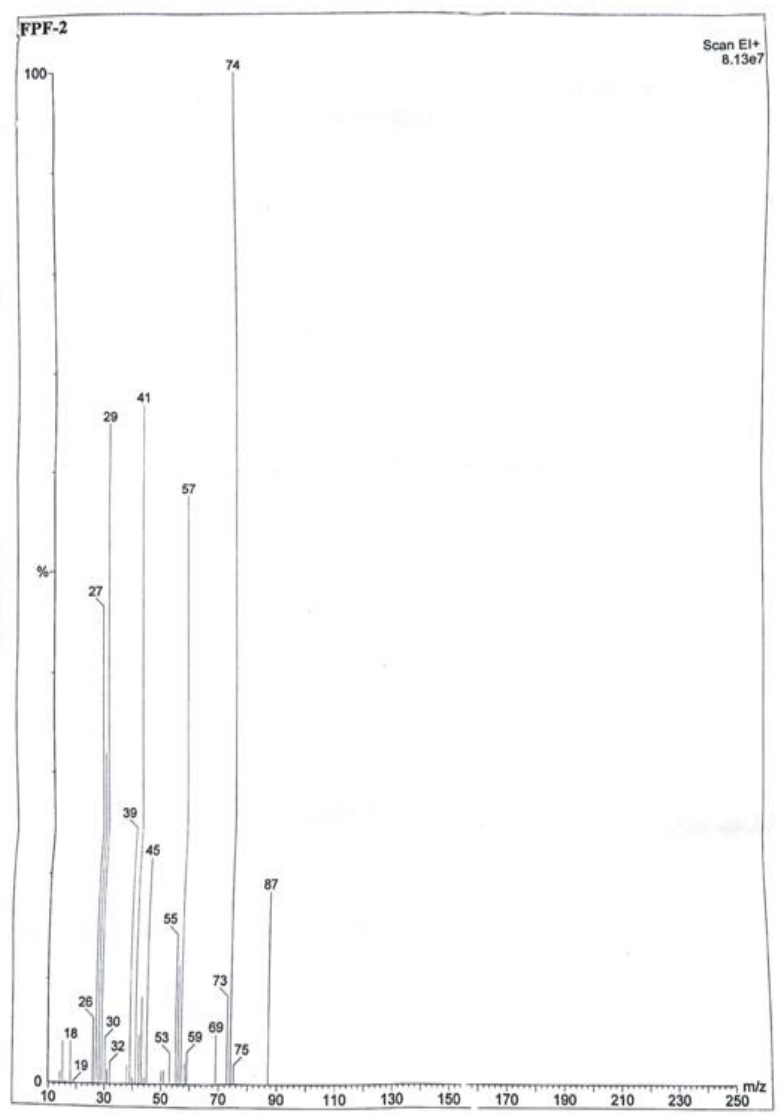

Figure 8: Mass Spectrum of Butanoic acid, 2-methyl-

\section{DISCUSSION}

Herbal remedies and alternative medicines are used throughout the world and in the past herbs have often represented the original sources of most drugs ${ }^{11}$ (Cooper, 2005). Results showed concentration dependent plant extract inhibition of fungal growth that may be due to increase in the concentration of secondary metabolites/active components on increasing the concentration. Tsai et al. (1999) suggests that some fungal pigments are natural products and associated with development of reproductive structures ${ }^{\mathbf{1 2}}$. Similarly, dark brown pigment called melanin is formed by oxidative polymerization of phenolic compounds and synthesized during spore formation. Alkaloids such as solanine and chaconine are discussed as resistance factors of potato against Alternaria solani ${ }^{\mathbf{1 3}}$ (Sinden et al., 1972).

Versha et al. (2003) reported that various fractions i.e. petroleum ether, chloroform, ethyl acetate and methanol of Alstonia scholaris leaf powder exhibit significant antimicrobial activity against the test pathogens and strongest antifungal activity against $A$. niger and $A$. flavus was observed with chloroform fraction ${ }^{14}$. Antifungal activity of petroleum ether, chloroform and acetone and ethanol extracts of Calendula officinalis against A. fumigatus, Rhizopus japonicum, C. albicans, C. tropicalis etc. has been investigated by Kasiram et al., 2000. Rao et al. (2006) reported that alcohol extracts of some medicinal plants showed most significant antifungal activity as compared to other extracts prepared in different solvents ${ }^{15},{ }^{16}$. Presence of anthraquinone glycosides, sennosides A \& B, rhein and its glucoside, barbaloin, aloin, formic acid, butyric acid and their ethyl esters and oxalic acid, pectin and tannin in Cassia fistula fruit pulp has been reported by Agarwal and Paridhavi, $2005^{17}$.

Further separation and characterization of active principle from column fractions of $C$. fistula using GCMS analysis reveals the presence of butanoic acid, 2methyl-, Penthiophane (2H-Thiopyran, tetrahydro) and Isopropylacetate (Acetic acid, 1-methylethyl ester). The antifungal activity of butanoic acid, 2-methyl- and Penthiophane (2H-Thiopyran, tetrahydro) was already reported (Singh et al., 2003; Mickevičienè et al., 2015) ${ }^{\mathbf{1 8}, 19}$. However, Isopropylacetate (Acetic acid, 1methylethyl ester) not yet reported for antimicrobial activity in literature. The presence of these compounds in C. fistula fruit pulp extracts was also supported by Anitha and Miruthula, (2014) ${ }^{\mathbf{2 0}}$. Hence, present study deals with the extract preparation, fractionation and characterization of active antimicrobial compounds from Cassia fistula fruit pulp.

\section{CONCLUSION}

In the present study it can be concluded by the observations that treatment with chloroform extract of Cassia fistula leads the inhibition of conidiation, mycelial growth and morphological alterations in conidiophore hence responsible for conversion of pathogenic form of test fungus into non pathogenic form. Separation and identification of active compounds was done by column chromatography (CC) and GC-MS. Three compounds were obtained in GC MS analysis. 
These compounds are responsible for antimicrobial activity of Cassia fistula fruit pulp. Further studies, will be included incorporation of active compounds to NMR and IR for molecular characterization and subsequent drug designing process.

\section{REFERENCES}

1. Lange L, Breinholt J, Rasmussen FW, Nielsen RI. Microbial fungicides-the natural choice. Pestic Sci. 1993; 39:155-160.

2. Wilson CL, Solar JM, El-Ghaouth A, Wisniewski ME. Rapid evaluation of plant extracts and essential oils for antifungal activity against Botrytis cinerea. Plant Dis. 1997; 81:204-210.

3. Polya G. Gene expression, cell division and apoptosis, In: Biochemical targets of plant bioactive compounds, Taylor \& Francis, London, 2003.

4. Nadkarni KM. Indian Materia Medica, Bombay Popular Prakashan. 2009; 1:285-286.

5. Simmons E. Alternaria themes and variations (244-286) species on Solanaceae. Mycotaxon. 2000; 75:1-115.

6. Heaney SP, Hall AA, Davies SA, and Olaya G. Resistance to fungicides in the QoI-STAR cross resistance group: Current perspectives. Pages 755-762 in: Brighton Crop Protection Conference-Pests and Diseases- 2000. Vol. 2. Major Print, Nottingham, UK, 2000.

7. Tuzun S and Kloepper J. Practical application and implementation of induced resistance. In: Hammerschmidt R, Kuc J, eds. Induced Resistance to Disease in Plants. Amsterdam: Kluwer Academic Publications, 1995; 152- 168

8. Harborne JB. Methods of plant analysis. In phytochemical methods. London, NewYork: Chapman and hill, 1984; 05-06.

9. Collee FG, Miles RS, Watt B. Test for identification of bacteria. In: Mackie and McCartney Practical Medical Microbiology. Singapore: Longman Singapore publishers Ltd. 1996; 131-150.

10. Groover RK, Moore JD. Toxicometric studies of Fungicides against the brown root organisms Sclerotinia fructicola and $\mathrm{S}$ laxa. Phytopathology. 1962; 52:876-880.

11. Cooper EL. CAM, eCAM, bioprospecting: the 21st century pyramid. Evid Based Complement Altern Med. 2005; 2:125 127.
12. Tsai HF, Wheeler MH, Chang YC, Knon-Chung KJ. A developmentally regulated gene clusters involved in conidial pigment biosynthesis in Aspergillus fumigatus. J Bacteriol. 1999; 181:6469-6477.

13. Sinden SL, Goth RW, O'Brien, MJ. Effect of potato alkaloids on the growth of Alternaria solani and their possible role as resistance factors in potatoes. Phytopathology. 1972; 63,303307.

14. Versha P, Ghosh B, Anroop B, Ramanjit M. Antimicrobial activity of Alstonia scholaris leaf extract. Indian Drugs.2003; 40:412-413.

15. Kasiram K, Sakharkar PR, Patil AT. Antifungal activity of Calendula officinalis. Ind J Pharmaceut Sci. 2000; 6:464-466.

16. Rao MR, Reddy IB, Raman T. Antimicrobial activity of some Indian medicinal plants. Ind J Microbiol. 2006; 46:259-262.

17. Agarwal SS, Paridhavi M. Clinically useful herbal drugs, Ahuja Publishing House, 2005; 281-282.

18. Singh U, Raju B, Lam S, Zhou J, Gadwood RC, Ford CW, Zurenko GE, Schaadt RD, Morin SE, Adams WJ, Friis JM, Courtney M, Palandra J, Hackbarth CJ, Lopez S, Wu C, Mortell KH, Trias J, Yuan Z, Patel DV, Gordeev MF. New Antibacterial tetrahydro-4(2H)-thiopyran and thiomorpholine S-oxide and S,S-dioxide phenyloxazolidinones. Med Chem Lett. 2003; 13:4209-4212.

19. Mickevičienė K, Baranauskaitė R, Kantminienė K, Stasevych M, Komarovska-Porokhnyavets O, Novikov V. Synthesis and Antimicrobial Activity of N-Substituted- $\beta$-amino Acid Derivatives Containing 2-Hydroxyphenyl, Benzo[b]phenoxazine and Quinoxaline Moieties. Molecules. 2015; 20:3170-3189.

20. Anitha J., Miruthula S. Anti-inflammatory and phytochemicals analysis of Cassia fistula Linn. fruit pulp extracts. Int J Pharmacogn.2014; 1:207-215. 